\title{
1205Lu Human Metastatic Melanoma Cells, not Human!
}

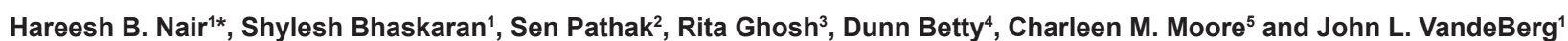

${ }^{1}$ Southwest National Primate Research Center, Texas Biomedical Research Institute, P.O. Box 760549, San Antonio, TX 78245-0549, USA

${ }^{2}$ Department of Genetics, Unit \# 1010, The University of Texas M.D. Anderson Cancer Center, 1515 Holcombe Boulevard, Houston, TX 77030, USA

${ }^{3}$ Department of Urology, University of Texas Health Science Center at San Antonio, 7703Floyd Curl Drive, San Antonio TX 78227, USA

${ }^{4}$ Department of Clinical Lab Science, University of Texas Health Science Center at San Antonio, 7703Floyd Curl Drive, San Antonio TX 78227, USA

${ }^{5}$ Department of Cellular and Structural Biology, University of Texas Health Science Center at San Antonio, 7703Floyd Curl Drive, San Antonio TX 78227, USA

Malignant melanoma is a devastating disease with an increase of incidence year by year despite of the scientific innovations. Understanding the basic biology and signaling pathways that operates in melanoma are inevitable to develop targeted therapeutics and personalized therapies against this disease. Even though emerging preclinical models of melanoma in different organisms has vastly contributed to the recent developments in the melanoma therapy, cell lines and cell culture models presented the initial and valuable insights regarding the basic understanding of the cellular mechanisms that operates in different types of melanomas based on their mutation status. Many human melanoma cell lines has been derived to study the role different gene mutations, $1205 \mathrm{Lu}$ cells, is one among them which harbor BRAFV600E and CDK4 mutations [1]. This cell line has been widely used by melanoma researchers around the globe for addressing their research questions [2,3]. In a recent issue of Nature Medicine, Gembarska et al. [2], have demonstrated that MDM4 is a key therapeutic target in cutaneous melanoma including1205Lu cells. Our laboratory experiments with 1205Lu WC00058 cells (Coriell Institute of Medical Research, Camden, NJ) has confirmed that this is not a human cell line since there is a major contamination (70-80\%) of mouse chromosomes in it. It is apparent that metastatic melanomas classically show evidence of complex karyotypes with numerous structural and numerical aberrations and a high degree of aneuploidy [4]. It is crucial to use well characterized cell lines for biomedical research since these discoveries may lead to the development of novel molecular pathways and discovery of inhibitors that can target these signaling pathways in human melanomas [5]. Human cells contaminated with mouse chromosomes may not recapitulate to answer the questions in translational research or show desired activity in clinical trials. Based on our laboratory investigation, our recommendation to investigators is that to use only cytogenetically analyzed cells from the commercial repositories. Chromosome analysis of $1205 \mathrm{Lu}$ cells showed presence of about $80 \%$ mouse metaphases and about $20 \%$ human metaphases. A representative karyotype from a mouse metaphase has shown in the Figure1. The chromosome number in the mouse cells ranged from $62-$ 66 with the model chromosome number of 64 . Three clonal markers were present in these cells. The tentative identification of the markers are $\mathrm{M} 1=\operatorname{tandem} \mathrm{t}(4 \mathrm{q}: 11 \mathrm{q}), \mathrm{M} 2=\operatorname{tandem} \mathrm{t}(10 \mathrm{q}: 11 \mathrm{q})$ and $\mathrm{M} 3=\operatorname{tandem}$ $t(5 q: 16 q)$. Although we have demonstrated here only one melanoma cell line $1205 \mathrm{Lu}$, it might be an invaluable resource for the melanoma community since authenticated cell lines are unique tool for melanoma basic research, preclinical testing and translational research.

\section{References}

1. Smalley KS, Lioni M, Dalla Palma M, Xiao M, Desai B, et al. (2008) Increased cyclin D1 expression can mediate BRAF inhibitor resistance in BRAF V600Emutated melanomas. Mol Cancer Ther 7: 2876-2883.

2. Gembarska A, Luciani F, Fedele C, Russell EA, Dewaele M, et al. (2012) MDM4 is a key therapeutic target in cutaneous melanoma. Nat Med. doi:10.1038/ $\mathrm{nm} .2863$

3. Tsai J, Lee JT, Wang W, Zhang J, Cho H, et al. (2008) Discovery of a selective inhibitor of oncogenic B-Raf kinase with potent antimelanoma activity. Proc Nat Acad Sci USA 105: 3041-3046.

4. Höglund M, Gisselsson D, Hansen GB, White VA, Säll T, et al. (2004) Dissecting karyotypic patterns in malignant melanomas: temporal clustering of losses and gains in melanoma karyotypic evolution. Int J Cancer. 108: 57-65

5. Pathak S (1976) Chromosome banding techniques. J Reprod Med 17: 25-28.

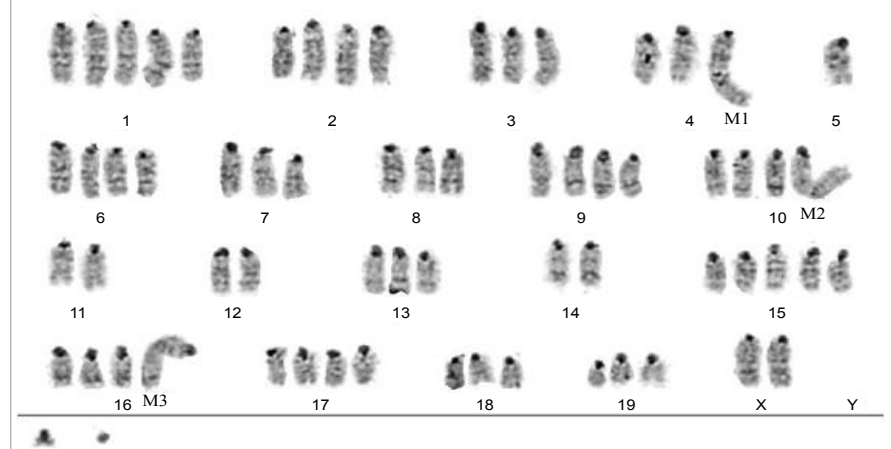

Figure 1: Representative karyotype from a mouse metaphase.

\begin{abstract}
*Corresponding author: Hareesh B Nair, PhD, Southwest National Primate Research Center, Texas Biomedical Research Institute, P.O. Box 760549, San Antonio, TX 78245-0549, USA, Tel: 210-258-9515; E-mail: hnair@txbiomedgenetics.org

Received February 25, 2013; Accepted February 28, 2013; Published March 03 2013

Citation: Nair HB, Bhskaran S, Pathak S, Ghosh R, Betty D, Moore CM, et al. (2013) 1205Lu Human Metastatic Melanoma Cells, not Human! J Cancer Sci Ther 5: 119-119. doi:10.4172/1948-5956.1000196

Copyright: $\odot 2013$ Nair HB, et al. This is an open-access article distributed under the terms of the Creative Commons Attribution License, which permits unrestricted use, distribution, and reproduction in any medium, provided the original author and
\end{abstract} source are credited. 